\title{
A Model on the Contribution of School Assets to the Achievement of Adolescents' Well-Being and Academic Performance
}

\author{
Miguel-Ángel Pertegal and Alfredo Oliva \\ Universidad de Sevilla (Spain)
}

\begin{abstract}
The aim of this study was to examine a model on the contribution of school assets on the development of adolescent's well-being and school success. The sample comprised 1944 adolescents (893 girls and 1051 boys) aged between 12 and 17 years $(M=14.4 ; S D=1.13)$, from secondary schools in Western Andalusia, which completed some self-report questionnaires. The results of structural equation modeling showed the goodness of fit of the initial theoretical model. This model confirmed the importance of school connectedness as a key factor in the relationships between other school assets (social climate; clarity of the rules and values, and positive opportunities and empowerment) and commitment to learning, academic performance and life satisfaction. However, the re-specification of the initial model considered two complementary paths with theoretical sense: first, a direct influence between clarity of the rules and values and commitment to learning, and second, between academic performance and life satisfaction. This model obtained better goodness of fit indices than the first one: $\chi^{2}=16.32 ; g l=8 ; p=.038 ; \chi^{2} / g l=2.04$; SRMR $=.018$; RSMEA $=.023$ $(95 \%$ C.I. $=.005 ; 040) ; \mathrm{NNFI}=.98 ; \mathrm{CFI}=.99$. From our study, the need to invest in initiatives focused on the promotion of adolescents' links with their school emerges as a key goal to contribute towards, at the same time, both a good academic performance and a better life satisfaction.
\end{abstract}

Received 13 April 2016; Revised 2 August 2017; Accepted 18 September 2017

Keywords: academic achievement, adolescent development, life satisfaction, School environment, structural equation modeling.

The possibility that the school can academically prepare students whilst promoting their psychological well-being is an ambitious goal, with such goals been often considered as not fully compatible (Marchesi \& Martín, 2002). However, in the last two decades, proposals have been made that claim that the development of socio-emotional competences and academic success can go hand in hand (Zins, Weissberg, Wang, \& Walberg, 2004).

Nowadays, the Positive Youth Development approach has driven the study of the positive aspects of psychological functioning among young adults and adolescents. This approach insists on the need to study two key aspects in order to understand a good personal development: the personal strengths or resources that contribute to such development and the positive characteristics or assets of the contexts or institutions that promote it (Lerner, 2009; Oliva, 2015).

Firstly, and in relation to the study of personal strengths of importance within the school environment, the role played by the maintenance of a solid

Correspondence concerning this article should be addressed to Miguel Ángel Pertegal. Dpto. Psicología Evolutiva y de la Educación. Universidad de Sevilla. C/Camilo José Cela, s/n. Sevilla, Spain. 41300. Phone: +34-954551722.

E-mail: mpertegal@us.es commitment to learning by students is noteworthy (Benson, Scales, Hamilton, \& Sesman, 2006). This commitment would be directly related to a fundamental educational goal, such as academic success, achieved through a good academic performance.

Secondly, it is also important to analyze the resources or assets present in the contexts in which adolescent life takes place and that can promote their positive development. Some examples of school assets could be: good relationships with peers, clarity of rules and values, empowerment and positive development opportunities, perceived teacher support, or the links created with the school itself.

Nevertheless, the Positive Youth Development model has not only shown interest in the analyses of the internal and external assets that optimize such development, but it has also aimed to study the goals that define a successful and healthy development during adolescence (Oliva et al., 2010). The present study focuses on two of these goals which the school should promote,

How to cite this article:

Pertegal, M.-A., \& Oliva, A. (2017). A model on the contribution of school assets to the achievement of adolescents' well-being and academic performance. The Spanish Journal of Psychology, 20. eXX. Doi:10.1017/sjp.2017.47 
that is, students' life satisfaction and their academic performance.

Life satisfaction is an indicator of subjective wellbeing, which can be conceptualized as a cognitive estimation of the quality of one's own life, a sort of global judgment that each person makes of his/her life as a whole, based on his/her own standards or criteria, regarding whether he/she likes the life he/she is living or whether he/she is achieving his/her aspirations (Diener, Scollon, \& Lucas, 2009).

The relevance of life satisfaction as a positive psychological indicator is beyond doubt, as high satisfaction has been associated with multiple benefits, both at a personal and socio-emotional level (better self-esteem, emotional intelligence, social competence, etc.) and at a school level (greater satisfaction and school adjustment, among others). Likewise, life dissatisfaction has been consistently related to various indicators of adolescent maladjustment (Gilman \& Huebner, 2006; Huebner \& Diener, 2008).

In particular, it is noteworthy that several previous studies have suggested strong positive associations, both between student commitment to learning and subjective well-being (Lewis, Huebner, Malone, \& Valois, 2011; Suldo, Shaffer, \& Riley, 2008) and a consistent relationship between life satisfaction and academic performance (Gilman \& Huebner, 2006; Proctor, Linley, \& Malby, 2010).

Obviously, in addition to the promotion of life satisfaction among students, it is also necessary to evaluate how schools contribute to the achievement of academic performance. Performance can be assessed either through standardized tests - objective academic performance - which allows for comparison between students, schools and countries; or through school grades, which, although their reliability and validity are questioned as a criterion for comparison, represent the real indicator of academic success (Martínez-Otero, 2009).

Among the resources and personal strengths of adolescents which contribute to explain their academic success, the role of their commitment to learning should be emphasized. Such student commitment should be considered not only as a fundamental process and predictor of academic success, but also as a school result in itself. In fact, commitment to learning is an increasingly important construct in North American and European education research as it is considered a key element for the improvement of school results (Furlong \& Christenson, 2008). However, despite its international relevance, students' commitment to learning is a scarcely researched construct hardly studied in Spain (Ros, Goikoetxea, Gairín, \& Lekue, 2012).

There are several proposals to conceptualize student commitment, among which Fredricks, Blumenfeld, and Paris' (2004) proposal can be highlighted. These authors considered three components for this commitment to learning: cognitive, behavioral and affective components. The present study focused on the cognitive dimension of commitment, which involves a psychological investment of students into school learning, and includes aspects such as the student's own perception of his/her effort, the assessment of the importance of studying as a goal, the persistence, and the desire to improve with his/her learning and to continue their studies in the future.

Beyond the importance of commitment to learning in the promotion of both life satisfaction and academic performance, a key purpose of the present research is to clarify the specific contribution of school assets to a positive adolescent development. That is, to clarify the characteristics that schools have that promote such development. We consider that the fundamental characteristics that characterize schools which can function as true promoters of the positive development of their students are:

a. The creation of a "positive environment" that represents a warm and secure climate among peers as a basis for coexistence within the school.

b. The establishment of a "school connectedness", which involves the development of a sense of belonging to the school and the development of links with the school's educators.

c. The construction of "a structured, organized and coherent educational environment about rules and values", which entails a clear guide for the regulation of students' behavior within the school.

d. The offer of "positive opportunities" for the development of skills and for the "empowerment" of adolescents.

A school with such positive traits or school assets, that is, with a good social climate, capable of bringing together positive people, places or environments and opportunities not only promotes good academic results (Starkman, Scales, \& Roberts, 2006), but also constitutes a context that promotes students' well-being and positive adolescent development (Gardner, Roth, \& Brooks-Gunn, 2008).

Regarding the literature on the prediction of adolescent well-being, the two most important school factors have been the close relationships between students and teachers and the links established with other students (Natvig, Albrektsen, \& Qvranstrom, 2003; Suldo, Riley, \& Shaffer, 2006). Such linkage is influenced, as some studies suggest, by characteristics of school functioning, such as the provision of positive opportunities or the perception of an educational coherence about rules and values (Gilman \& Huebner, 2006; Loukas, Suzuki, \& Horton, 2006). In this sense, we believe that 
positive links with the school can be a clear mediator between other perceived school assets and the achievement of life satisfaction (Tomyn \& Cummins, 2011).

Examining the research literature on school climate and performance, it can be concluded that school connectedness represents a key variable for predicting performance (Cohen, McCabe, Michelli, \& Pickeral, 2009). But it is mainly in the studies that analyze school connectedness where it appears as a decisive asset in the commitment to learning and in academic performance. Thus, students who feel attached to their school are more engaged with their studies and end up performing better (Blum, 2005).

The present study aims to empirically hypothesize and contrast how educational institutions, through their assets, can contribute to the joint achievement of two educational goals such as life satisfaction and academic performance. The importance of the mediating role of school connectedness in the relationship between other school assets and such goals is suggested. On the other hand, the study highlights how commitment to learning can mediate the relationship between school connectedness and academic performance.

\section{Proposed initial model and hypotheses}

Thus, as shown in Figure 1, the model initially proposed contemplates the following hypotheses:

H1: The exogenous variables, three school assets (clarity of rules and values; social climate; and empowerment and positive opportunities) will have a positive direct effect on the school connectedness.

$\mathrm{H} 2$ : Positive school connectedness will in turn show a positive direct effect on adolescent life satisfaction.

H3: The social climate among peers will also have a positive direct effect specifically on adolescent life satisfaction.

H4: School connectedness will have a positive indirect effect on academic achievement through commitment to learning.
H5: School connectedness will have a positive indirect effect on life satisfaction through academic performance.

H6: Life satisfaction will have a direct impact on academic performance.

It should be noted that the figures only show the structural part of the model, as the part that refers to the measures has already been published.

\section{Method}

\section{Participants}

The sample of this study consisted of 1944 adolescents, 1051 girls (54.1\%) and 893 boys (45.9\%) aged between 12 and 17 years $(M=14.40 ; S D=1.13)$ who were enrolled in compulsory secondary education in 20 schools across Western Andalusia.

An intentional sampling was used to select the schools taking part in the study in order to match different qualities of the sample units and to obtain the most diverse sample possible (Hernández, Fernández, \& Baptista, 2010). Therefore, sampling was carried out through quotas according to the following variables: a) size of the school (small: less than 600 students, large: more than 600 students), b) socioeconomic level of the area (medium-low and medium-high), c) size of the population where it is situated (small: less than 30,000 inhabitants, large: more than 30,000 inhabitants), and (d) ownership of the school (public or private). The distribution of the sample was balanced for all of the mentioned variables, with the exception of the ownership of the schools $(80 \%$ were public schools and $20 \%$ were private-semiprivate schools).

\section{Variables and instruments}

Next, the instruments that evaluate the constructs included in the model are presented, among which positive relationships were expected in all cases.

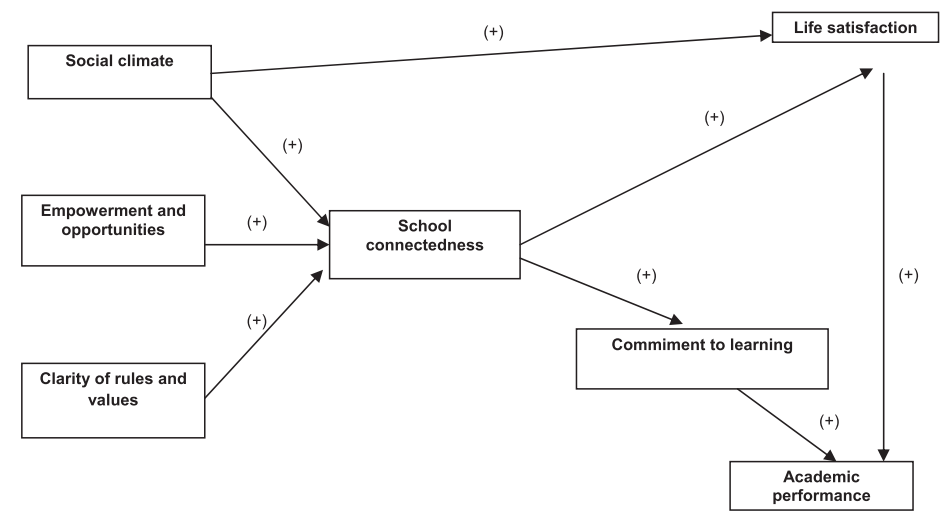

Figure 1. Graphic representation of the theoretical model initially proposed. 
Scale for evaluating school assets for positive adolescent development

This scale has been previously validated in our context with satisfactory goodness of fit indexes (Pertegal, Oliva, \& Hernando, 2015). It allows to evaluate the perception that adolescents have on different dimensions of the school in which they study. It consists of 30 items that must be scored on a scale between 1 and 7 . The scale offers, apart from the overall score, four partial scores:

Social Climate. This dimension includes six items referring to both the degree to which adolescents perceive the relationships between peers as good and to the perception of safety within the school. Reliability as indicated by Cronbach's alpha coefficient was .78.

School connectedness. This dimension evaluates through its seven items two aspects related to the connectedness to the school on behalf of the students: the degree to which adolescents have a sense of belonging and satisfaction with their own school, and the assessment of the support perceived from the teachers. The reliability obtained for this dimension was .81 .

Clarity of rules and values. This subscale consists of seven items. On the one hand, this dimension assesses the degree to which adolescents perceive the clarity of the limits regarding the existing rules of the school. On the other hand, it evaluates the perception of the coherence in the promotion of values in the school by the teachers with three other items. Reliability as indicated by Cronbach's alpha coefficient was .82 .

Empowerment and positive opportunities. It involves evaluating, through ten items, the resources and facilities of the school as opportunities; the offer of activities for the students, and the perception of student participation and its influence on the life of the school ("empowerment"). The reliability, as indicated by Cronbach's alpha coefficient, for this dimension was .83.

\section{Commitment to learning evaluation scale}

Given the lack of a specific instrument in our context that was easy to administrate, this scale was created and validated for this research with satisfactory goodness of fit indexes $\left(\chi^{2}=7.61 ; g l=3 ; p=.055 ;\right.$ RSMEA $=$ $.03 ; C F I=.99 ;$ NNFI $=.98)$. It evaluates the cognitive commitment to learning and studies on behalf of the students through five items (e.g., "I want to get through my studies" or "At school, I try to do my work as best I can"), scored on a scale between 1 and 7 . The scale offers a single overall score and obtained a Cronbach's alpha reliability coefficient of .81 .

\section{Life satisfaction assessment scale}

This instrument allows to evaluate adolescents' life satisfaction. It was developed and validated by Huebner in 1991 and the Spanish version has been validated recently (Galíndez \& Casas, 2010). It consists of a Likert scale (range $=1-7$ ) composed of seven items. It reached a reliability coefficient, with a Cronbach's alpha of $.81(M=5.22 ; S D=1.09$; range $=1-7)$.

\section{Academic performance}

Academic achievement was assessed through the collection of information on the grades obtained by the students in the course year prior to that of the study. These scores were coded on a scale of 1 to 6 , where 1 = "very poor", which normally meant several fails; 2 = "insufficient", which usually meant one or two fails, $3=$ equivalent to a general pass, and so on, $4=\operatorname{good}, 5=$ remarkable and $6=$ outstanding.

\section{Procedure}

This study followed a cross-sectional, non-experimental and correlational design (Hernández, Fernández, \& Baptista, 2010). Once the study was designed and approved by the Ethics Committee of the University of Seville, the participating schools were selected and visits were made to explain in detail the objectives of the study and the procedure to be carried out. The schools, in turn, informed families of the participation and characteristics of the study so as they could express their possible disagreement.

In each school, two classrooms of $2^{\text {nd }}$ year of compulsory secondary school ("Educación Secundaria Obligatoria, ESO" in Spanish), 2 classrooms of $3^{\text {rd }}$ year of ESO and 2 classrooms of $4^{\text {th }}$ of ESO were randomly chosen. The inclusion of groups from $1^{\text {st }}$ year of ESO was discarded as it was considered that the fact that the majority of $1^{\text {st }}$ year students had just started in that school and thus, made it highly unlikely that the school variables analyzed in the study had already had some influence on the students.

All participants were informed of the study's objective, and that it was voluntary. The confidentiality of responses and data management was assured. A passive consent procedure was used to obtain parental approval. The evaluation instruments were completed in two hour-long group sessions in which students were emphasized that they should answer with the utmost sincerity and honesty. These sessions were always conducted by at least one member of the research team.

\section{Data analyses}

Firstly, it should be noted that with regard to the treatment of missing data, the starting point was that if the number of invalid items on one of the scales exceeded $25 \%$, such data would be excluded from the analysis. As the missing values were less than that percentage, 
they were imputed using a regression model from the other valid items.

Subsequently, the descriptive statistics (mean and standard deviation) of the variables included in the study were calculated, as well as the bivariate correlations using the Pearson coefficient. For all of these previous analyzes, the SPSS 22.0 statistical package was used.

A structural equations analysis was chosen to be able to explore the possible relationships between the variables contemplated in the study. A multilevel analysis was not performed as when the intraclass correlations were calculated to evaluate the possible school effect for both academic performance and life satisfaction variables, these values were less than .10 (Hox, 2010).

The well-known Model Development Strategy in Statistics (Abad, Olea, Ponsoda, \& García, 2011) was followed. This strategy consists of starting from the conceptual model and adding, if it is necessary to achieve a good development and global fit, those effects that have theoretical sense. The final objective is that the adjusted model be as close to the conceptual model as possible and as parsimonious as possible.

In order to verify the appropriateness of the hypothesized model, the AMOS 22.0 program was used and the most used and recommended method of maximum likelihood was chosen, even if multivariate normality was not observed (Abad et al., 2011), as occurred in this case. At the same time, the possible existence of multicollinearity between variables was verified, yielding VIF values lower than 2 , both in relation to academic performance and life satisfaction.

Subsequently, the adjustment of the models was verified, firstly, from the absolute adjustment measures, $\chi^{2}$, the ratio between $\chi^{2}$ and degrees of freedom $\left(\chi^{2} / g l\right)$; SRMR (Standardized Root Mean Residual) and RMSEA (Root Mean Square Error of Approximation), and secondly, through the most commonly used relative fit indexes: NNFI (Non-Normed Fit Index) and CFI (Comparative Fit Index). For all of them, values above
.90 were set as acceptance threshold, .95 for CFI and less than .05 for RMSEA, according to the recommendations of Abad et al. (2011).

\section{Results}

Firstly, both the descriptive statistics of the variables used in this study and the correlations obtained between school assets and the different dependent variables of the study: commitment to learning, academic achievement and life satisfaction are presented.

As can be observed in Table 1, the school context was perceived by students as being rich in assets, being the school connectedness and the clarity of rules and values the most valued assets. At the same time, the data showed that school assets correlated more with life satisfaction than with academic performance. Thus, on the one hand, it is worth noting that a complex structure of correlations of life satisfaction with all school assets was found, and on the other hand, that commitment to learning was the variable that most correlated with academic performance.

The analysis of the fit of the proposed model to the empirical data matrix was performed with the AMOS 22.0 program, following the phases usually proposed (identification, assessment of fit, re-specification and model improvement). After verifying that none of the infringing estimates would invalidate the estimate, the analysis using the maximum likelihood estimation $(M L)$ method was performed, in order to test the set of explanatory relationships hypothesized in the initial model.

Firstly, when the analysis with AMOS was performed, the model was identified. In Figure 2, the initially proposed model and its standardized coefficients for the direct and indirect effects - all of which were significant $(p<.01)$ are presented. These effects will not be discussed here, as first the adjustment indexes obtained were examined to assess the need to re-specify this model for its possible improvement.

The initial model obtained a value of $\chi^{2}=110.97$; $g l=10 ; p<.001 ; \chi^{2} / g l=11.09$. It should be noted that this statistic is very sensitive to the size of the sample.

Table 1. Descriptive statistics and correlations between the different variables of the study

\begin{tabular}{|c|c|c|c|c|c|c|c|c|c|c|}
\hline & 1 & 2 & 3 & 4 & 5 & 6 & 7 & Range & $M$ & $S D$ \\
\hline Social climate & - & & & & & & & $1-7$ & 4.29 & .99 \\
\hline School connectedness & $.31^{* *}$ & - & & & & & & $1-7$ & 5.28 & 1.042 \\
\hline Clarity of rules and values & $.22^{* *}$ & $.53^{* *}$ & - & & & & & $1-7$ & 5.37 & 1.01 \\
\hline Empowerment and opportunities & $.25^{* *}$ & $.56^{* *}$ & $.56^{* *}$ & - & & & & $1-7$ & 4.48 & 1.01 \\
\hline Commitment to learning & $.06^{* *}$ & $.28^{* *}$ & $.26^{* *}$ & $.16^{* *}$ & - & & & $1-7$ & 5.58 & .83 \\
\hline Academic performance & .00 & $.09^{* *}$ & $.05^{*}$ & .03 & $.27^{* *}$ & - & & $1-6$ & 3.41 & 1.80 \\
\hline Life Satisfaction & $.18^{* *}$ & $.23^{* *}$ & $.13^{* *}$ & $.16^{* *}$ & $.20^{* *}$ & $.14^{* *}$ & - & $1-7$ & 5.23 & 1.09 \\
\hline
\end{tabular}

${ }^{*} p<.05 ;{ }^{* *} p<.01$. 


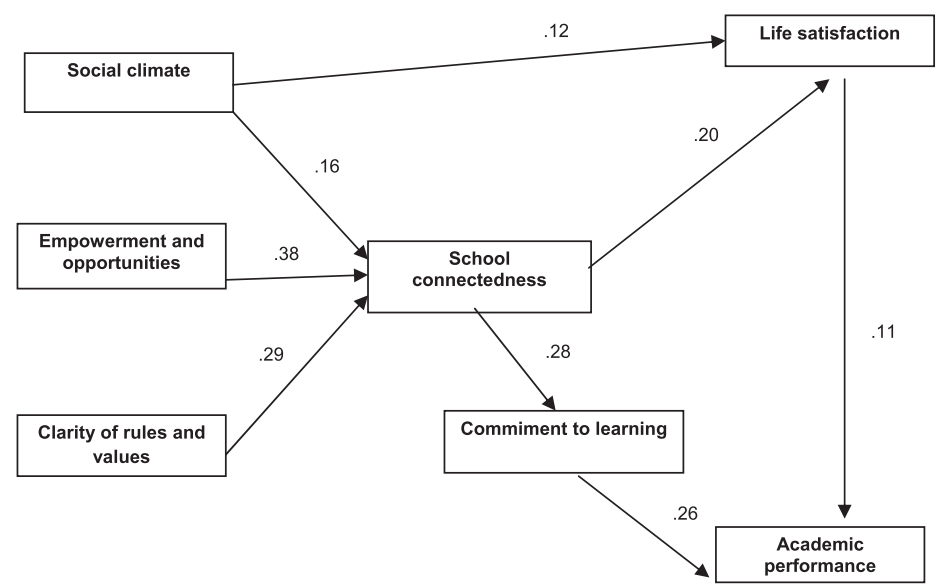

Figure 2. Standardized coefficients of the theoretical model initially proposed.

Therefore, in the case of large samples, such as this one, it usually leads to rejection of the proposed model, having an associated $p$ less than .05 .

The model initially proposed also obtained the following fit indexes: $S R M R=.045 ; R S M E A=.07 ; N N F I=$ $.91 ; C F I=.96$. Despite obtaining values that indicated a good fit in most indices, the RSMEA, which is the most recommended indicator, only presented an acceptable fit, as it was not below .05, which would represent an optimal fit. Therefore, the modification indexes (M.I.) suggested by the AMOS program in the output were considered in order to evaluate the need for re-specification of the model to improve its fit, provided that it had theoretical sense.

After verifying the magnitude and significance of these indexes, these were taken into account to re-specify another model. This led to test the inclusion, first, of a positive direct effect of the asset of clarity of rules and values on commitment to learning (M.I. = 50.96; P.C. $=.20)$ and, subsequently, another positive direct effect of commitment to learning on life satisfaction (M.I. = 27.16; P.C. $=.09)$.
The re-specified model and its parameters can be examined in Figure 3, which in their entirety obtained significance at level $p<.01$.

The fit indices of the two models presented for comparison can be examined in Table 2 .

The second proposed model obtained the following absolute fit measures: $\chi^{2}=16.32 ; d f=8 ; p=.038$. In the case of large samples, it is more useful to use the $\chi^{2} / d f$ ratio to compare plausible models and to evaluate the significance of the variation in $\chi^{2}$. The $\chi^{2} / d f$ value was 2.04 and the chi squared variation was statistically significant, following the usual recommendation of being less than 2 or 3 .

In addition, this proposed model obtained a $S R M R=$ .018 and a RSMEA with a value of .023 ( $95 \%$ Confidence Interval $=.005 ; .040)$. These values were lower than .05 , which is considered a good fit, and even by other authors, such as Steiger (2007), is qualified as an excellent fit when the RSMEA is below .03 .

In order to finish elucidating which model is best, the incremental fit measures usually used for the comparison of plausible models were examined. The second

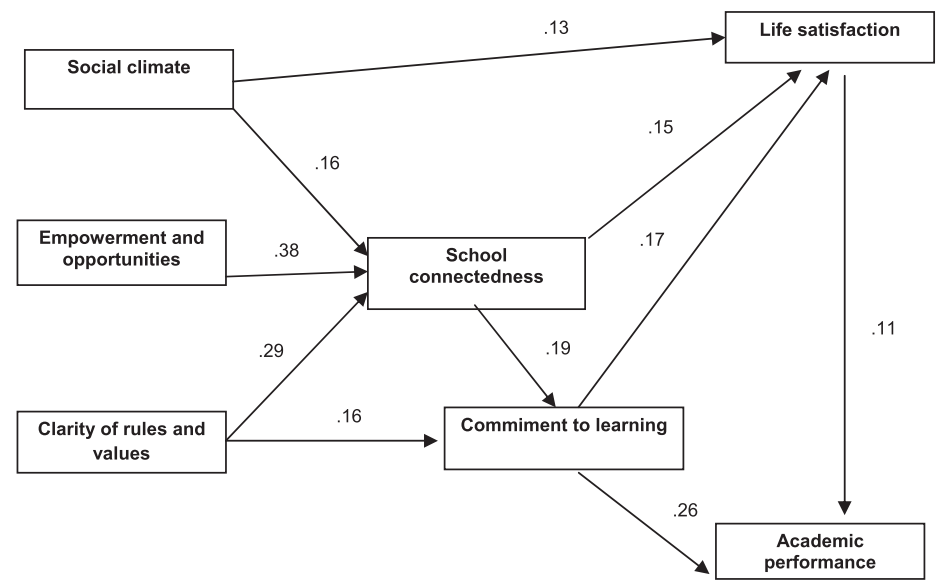

Figure 3. Standardized coefficients of the re-specified model. 
Table 2. Comparison of the fit indexes for the two possible models

\begin{tabular}{lrrrrrrr}
\hline Fit indexes & \multicolumn{1}{c}{$\chi^{2}$} & $D f$ & $\chi^{2} / d f$ & SRMR & RMSEA & NNFI & CFI \\
\hline Initial model & 110.97 & 10 & 11.09 & .045 & .07 & .91 & .96 \\
Re-specified model & 16.32 & 8 & $2.04^{* *}$ & .018 & .023 & .98 & .99 \\
\hline
\end{tabular}

${ }^{* *} p<.01 ;$ Note: $\chi^{2}=$ chi squared; $d f=$ degrees of freedom; $S R M R=$ Standardized Root Mean Residual; RMSEA = Root Mean Square Error of Approximation; NNFI = Non-Normed Fit Index; CFI = Comparative Fit Index.

model obtained the following values in these indexes: $N N F I=.98 ; C F I=.99$.

First, the CFI index, the most recommended by $\mathrm{Hu}$ and Bentler, (1999) was considered. The CFI obtained from the re-specified model was .99 , resulting in a favorable increase to it, clearly significant as the increase was higher than .01.

It is also convenient to examine the NNFI index, being one of the factors less affected by sample size and that penalizes non-parsimonious or complex models, such as this one, better than the CFI. An obtained NNFI of .98 is an excellent fit of the model.

At present, none of these indices alone is sufficient to justify and determine if a model fits the data adequately. Authors such as Abad et al. (2011) consider that an adequate combination of indices, which depend less on sample size and is adequate given the complexity of this model is: NNFI; RMSEA and CFI. Based on this combination, the re-specified model seems to be better due to its better fit and by its greater theoretical sense.

After choosing the second model, the coefficients obtained are discussed next, disaggregating the direct and indirect and total effects with respect to the dependent variables of the study.

Figure 3 presents the final model with the standardized coefficients, in which all effects were positive and with a $p<.01$. This model explains a variance of $9.9 \%$ with respect to life satisfaction and of $9.3 \%$ in relation to academic performance.

In this figure, it can be observed how three school assets (the clarity of rules and values, $\gamma=.30$; the perception of positive opportunities, $\gamma=.35$; and to a lesser extent, the social climate, $\gamma=.17)$, are shown as positive predictors of connectedness with the school $\left(R^{2}=.43\right)$. School connectedness, which plays a central role in our model as a mediator variable, proved to be a direct positive predictor of both life satisfaction $(\beta=.15)$ and commitment to learning $(\beta=.19)$, and indirectly, through the latter $(\beta=.28)$ on academic performance.

On the other hand, there were two direct effects of another school asset, not mediated by school connectedness. One is the influence of good social climate amongst peers on life satisfaction $(\gamma=.13)$ and the other, which was added in the re-specified model about the influence of the school asset "clarity of rules and values" on commitment to learning $(\gamma=.16)$. To complete the model, it should be noted that there would be a positive direct effect of commitment to learning on life satisfaction $(\beta=.17)$, and a final direct effect of the influence of life satisfaction on improving academic performance $(\beta=.11)$.

\section{Discussion}

The main purpose of this study was to test the plausibility of a structural model on the specific contribution of school assets to the promotion of life satisfaction and academic performance during adolescence. In this sense, the goodness of absolute and relative of fit indices confirmed the validity of the re-specified model. This validation of the model shows that, at least in the schools of our sample, some assets present in the school context were related to the achievement of both, the life satisfaction and academic performance objectives that should not be understood as antagonistic, but as complementary and interrelated (Marchesi \& Martín, 2002).

The results of the study corroborate that a part of the observed variance of both academic performance - $9.3 \%$ and life satisfaction - 9.9\% -was explained by school assets. These findings can lead to the hypothesis that "school matters" as a positive development context, as these results exceed the usual relative magnitude of school effects found in some studies - around or below $5 \%$ - both on academic performance and on the variables related to the socioemotional development of students (Murillo, 2005; Pertegal, 2014). Therefore, these results are in line with the empirical evidence, mainly from the USA, which increasingly emphasizes the connection between academic performance, the development of socio-emotional competences and the well-being of adolescents, in the sense that the promotion of positive development has the indirect effect of improving school performance (Zins et al., 2004).

However, the main finding of this study, at least from a theoretical point of view, is the centrality of the positive school connectedness, as a school asset that would mediate the relationship between the other three school assets (social climate among peers, perceived 
clarity of rules and values, and the perception of positive opportunities and empowerment) and life satisfaction and commitment to learning. The establishment of positive connectedness is not only one of the five dimensions or Cs that characterize adolescent positive development, according to Lerner (2009), but its study has taken a leading role in the last decade, making very suggestive proposals around the school connectedness construct (Blum, 2005; McNelly, 2004). The connectedness with adults have been widely considered to be a protective factor in adolescents' development (Roth \& Brooks-Gunn, 2003), but more and more empirical evidence is accumulating on their contribution to both adolescents' well-being (Huebner \& Diener, 2008; Suldo et al., 2006) and academic success (Blum, 2005; Starkman et al., 2006).

Another relevant empirical finding was the inclusion in the definitive model of two additional pathways: the positive direct effect of the asset of clarity of rules and values on academic performance and the positive direct effect of commitment to learning on life satisfaction. These hypotheses were contrasted and accepted by having a great theoretical sense, although they were not contemplated initially. It is congruent with the literature on school climate, that a good evaluation of the educational action of teachers (the perception of the clarity of rules and values by the students) has a positive influence on the development of a greater commitment to learning and studies (Cohen et al., 2009), and that this also results in improving life satisfaction, if it is considered as a vital and developmental task specific and essential to adolescence (Lerner, 2009).

Among the limitations of this study, the crosssectional nature of our research is noteworthy, but above al, its correlational design, which does not allow us to draw any conclusions on the causal relations hypothesized in the model. In addition, another limitation inherent to the purpose of the study is that we have sought to isolate and exclusively contemplate the influence of school assets on adolescents' well-being and school success, but this does not deny the decisive contribution of other developmental contexts, such as family assets, to such indicators of positive adolescent development.

In short, the present work aims to highlight the relative but important contribution of certain assets that characterize the school as a context of positive development for the promotion of adolescents' well-being and school success. Among these assets, the positive links with the school and with teachers could play a central and decisive role. Therefore, we consider it necessary that the development of school connectedness and the promotion of well-being are contemplated as goals and educational aims in themselves, beyond academic performance. On the one hand, the development of positive links with the school contributes to a greater commitment to learning and this, in turn, leads to a better academic performance. On the other hand, the development of greater links with the school will result in an increase in life satisfaction of our adolescents, which will have an added effect of improving their academic performance. Nevertheless, we believe that the school's contribution to the adolescent's well-being and development could be increased and optimized with the implementation of certain intervention strategies and programs that seek, with a positive approach, to promote competences and adolescent development (Oliva, 2015).

\section{References}

Abad F. J., Olea J., Ponsoda V., \& García C. (2011). Medición en ciencias sociales y de la salud [Measurement in social sciences and health]. Madrid, Spain: Síntesis.

Benson P. L., Scales P. C., Hamilton S. F., \& Sesman A. Jr. (2006). Positive youth development: Theory, research and applications. In R. M. Lerner (Ed.), Theoretical models of human development (pp. 894-941). Hoboken, NJ: John Wiley \& Sons.

Blum R. (2005). School connectedness: Improving the lives of students. Baltimore, MD: Johns Hopkins Bloomberg School of Public Health.

Cohen J., McCabe E. M., Michelli N. M., \& Pickeral T. (2009). School climate: Research, policy, teacher education and practice. Teachers College Record, 111, 180-213.

Diener E., Scollon C. N., \& Lucas R. E. (2009). The evolving concept of subjective well-being: The multifaceted nature of happiness. In E. Diener (Ed.), Assessing well-being. The collected works of Ed Diener (pp. 67-100). New York, NY: Springer.

Fredricks J. A., Blumenfeld P. C., \& Paris A. H. (2004). School engagement: Potential of the concept, state of the evidence. Review of Educational Research, 74, 59-109. https://doi.org/10.3102/00346543074001059

Furlong M. J., \& Christenson S. L. (2008). Engaging students at school and with learning: A relevant construct for all students. Psychology in the Schools, 45, 365-368. https: / / doi.org/10.1002/pits.20302

Galíndez E., \& Casas F. (2010). Adaptación y validación de la Students' Life Satisfaction Scale (SLSS) con adolescentes [Adaptation and validation of the Students' Life Satisfaction Scale (SLSS) with teenagers]. Estudios de Psicología, 31, 79-87.

Gardner M., Roth J., \& Brooks-Gunn J. (2008). Adolescents' participation in organized activities and developmental success two and eight years after high school: Do sponsorship, duration, and intensity matter? Developmental Psychology, 44, 814-830. https:/ / doi.org/10.1037/ 0012-1649.44.3.814

Gilman R., \& Huebner E. S. (2006). Characteristics of adolescents who report very high life satisfaction. Journal of Youth and Adolescence, 35, 293-301. https: / / doi.org/ 10.1007/s10964-006-9036-7

Hernández S. R., Fernández C., \& Baptista L. P. (2010). Metodología de la Investigación [Research Methodology]. (5 Ed.). México: Mc Graw Hill. 
Hox J. (2010). Multilevel analysis: Techniques and applications (2 ${ }^{\text {a }}$ Ed.). New York, NY: Routledge.

Huebner E. S. (1991). Further validation of the Students Life Satisfaction Scale: The independence of satisfaction and affect rating. Journal of Psychoeducational Assessment, 9, 363-368. https:/ / doi.org/10.1177/073428299100900408

Huebner E. S., \& Diener C. (2008). Research on life satisfaction of children and youth: Implications for the delivery of school-related services. In M. Eid \& R. Larsen (Eds.), The science of subjective well-being (pp. 376-392). New York, NY: Guilford Press.

Hu L., \& Bentler P. M. (1999). Cutoff criteria for fit indexes in covariance structure analysis: Convectional criteria versus new alternatives. Structural Equation Modeling, 6(1), 1-55. https://doi.org/10.1080/10705519909540118

Lerner R. M. (2009). The positive youth development perspective: Theoretical and empirical bases of a strengths-based approach to adolescent development. In S. J. Lopez \& C. R. Snyder (Eds.), Oxford handbook of positive psychology (2 ${ }^{\text {nd }}$ Ed., pp. 149-163). New York, NY: Oxford University Press.

Lewis A. D, Huebner E. S., Malone P. S., \& Valois R. F. (2011). Life satisfaction and student engagement in adolescents. Journal of Youth Adolescence, 40, 249-262. https://doi.org/10.1007/s10964-010-9517-6

Loukas A., Suzuki R., \& Horton K. D. (2006). Examining school connectedness as a mediator of school climate effects. Journal of Research on Adolescence, 16, 491-502. https: / / doi.org/10.1111/j.1532-7795.2006.00504.x

Marchesi A., \& Martín E. (2002). Evaluación de la educación secundaria. Fotografía de una etapa polémica [Evaluation of secondary education. A photograph of a controversial stage]. Madrid, Spain: Ediciones SM.

Martínez-Otero V. (2009). Diversos condicionantes del fracaso escolar en educación secundaria [Different conditions of school failure in secondary education]. Revista Iberoamericana de Educación, 51, 67-85.

McNelly C. (2004). Connection to school as an indicator of positive development. In L. Lippman \& K. Moore (Eds.), Indicators of positive youth development (pp. 289-304).

New York, NY: Kluwer academic/Plenum Press.

Murillo F. J. (2005). Investigación sobre eficacia escolar [Research on school effectiveness]. Barcelona, Spain: Octaedro.

Natvig G. K., Albrektsen G., \& Qvarnstrom U. (2003). Associations between psychosocial factors and happiness among school adolescents. International Journal of Nurse Practitioners, 9, 166-175. https:/ / doi.org/10.1046/ j.1440-172X.2003.00419.x

Oliva A. (Coord.) (2015). Desarrollo positivo adolescente [Positive adolescent development]. Madrid, Spain: Síntesis.
Oliva A., Ríos M., Antolín L., Parra A., Hernando A., \& Pertegal M. A. (2010). Más allá del déficit: Construyendo un modelo de desarrollo positivo adolescente [Beyond the deficit: Building a model of positive youth development model]. Infancia y Aprendizaje, 33, 223-234.

Pertegal M. A. (2014). Los centros de educación secundaria como promotores del desarrollo positivo adolescente [The secondary schools as promoters of positive adolescent development]. (Published doctoral dissertation). Universidad de Sevilla, Spain.

Pertegal M. A., Oliva A., \& Hernando A. (2015). Evaluating the school assets that promote positive adolescent development from the perspective of the student [La evaluación de los activos escolares para el desarrollo positivo adolescente desde la perspectiva del alumnado]. Cultura y Educación: Culture and Education, 27, 33-63. https: / doi.org/10.1080/11356405.2015.1006849

Proctor C., Linley P. A., \& Malby J. (2010). Very happy youths: Benefits of very high life satisfaction among adolescents. Social Indicators Research, 98, 519-532. https:/ / doi.org/10.1007/s11205-009-9562-2

Ros I., Goikoetxea J., Gairín J., \& Lekue P. (2012). Student engagement in the school: Interpersonal and inter-center differences. Revista de Psicodidáctica, 17, 291-307.

Roth J. L., \& Brooks-Gunn J. (2003). Youth development programs: Risk, prevention and policy. Journal of Adolescent Health, 32, 170-182. https://doi.org/10.1016/ S1054-139X(02)00421-4

Starkman N., Scales P., \& Roberts C. (2006). Great places to learn: Creating asset-building schools that help students succeed (2nd Ed.). Minneapolis, MN: Search Institute.

Steiger J. H. (2007). Understanding the limitations of global fit assessment in structural equation modeling. Personality and Individuality Differences, 42, 893-898. https://doi.org/ 10.1016/j.paid.2006.09.017

Suldo S. M., Riley K. R., \& Shaffer E. J. (2006). Academic correlates of adolescents' life satisfaction. School Psychology International, 27, 567-582. https:/ / doi.org/10.1177/ 0143034306073411

Suldo S. M., Shaffer E. J., \& Riley K. N. (2008). A socialcognitive-behavioral model of academic predictors of adolescents' life satisfaction. School Psychology Quarterly, 23, 56-69. https: / / doi.org/10.1037/1045-3830.23.1.56

Tomyn A. J., \& Cummins R. A. (2011). The subjective wellbeing of high-school students: Validating the personal wellbeing index-school children. Social Indicators Research, 101, 405-418. https://doi.org/10.1007/s11205-010-9668-6

Zins J., Weissberg R., Wang M., \& Walberg H. (2004). Building academic success on social and emotional learning: What does the research say? New York, NY: Teachers College Press. 